\title{
Condensate banking removal: study on ultrasonic amplitude effect
}

\author{
Aieshah Ainuddin ${ }^{1} \cdot$ Nabilla Afzan Abdul Aziz ${ }^{1}$ (]) Nor Akmal Affandy Mohamed Soom ${ }^{1}$
}

Received: 16 November 2020 / Accepted: 3 August 2021 / Published online: 21 August 2021

(c) The Author(s) 2021

\begin{abstract}
Hydrocarbons in a gas condensate reservoir consist of a wide variety of molecules which will react varyingly with the change of pressure inside the reservoir and wellbore. The presence of heavier ended hydrocarbons such as C5 and above, condensate banking will occur as pressure depletes. Pressure drop below dew point pressure causes condensate buildup which will give a negative impact in the productivity index of a gas condensate reservoir. Gas condensate reservoirs experience liquid drop out when pressure depletion reaches below dew point pressure. This occurrence will eventually cause condensate banking over time of production where condensate builds up in pore spaces of near-wellbore formations. Due to increase in condensate saturation, gas mobility is reduced and causes reduction of recoverable hydrocarbons. Instead of remediating production loss by using unsustainable recovery techniques, sonication is used to assist the natural flow of a gas condensate reservoir. This study aims to evaluate the effects of various ultrasonic amplitudes on condensate removal in a heterogenous glass pack in flowing conditions with varying exposure durations. Experiments were conducted by using n-Decane and a glass pack to represent condensate banking and near-wellbore area. Carbon dioxide was flowed through the pack to represent flowing gas from the reservoir after sonication of $10 \%, 50 \%$ and $100 \%$ amplitudes $(20 \mathrm{kHz}$ and 20 Watts). Analysis of results shows recovery of up to $17.36 \%$ and an areal sweep efficiency increase in $24.33 \%$ after sonication of $100 \%$ amplitude for 120 min due to reduction in viscosity. It was concluded that sweeping efficiency and reciprocal mobility ratio are increased with sonication of $100 \%$ amplitude for $120 \mathrm{~min}$. This indicates that mobility of n-Decane is improved after sonication to allow higher hydrocarbon liquid production. Insights into the aspects of the mechanical wave are expected to contribute to a better understanding of tuning the sonic wave, to deliver remarkable results in a closed solid and fluid system. This form of IOR has not only proved to be an effective method to increase productivity in gas condensate wells, but it is also an environmentally sustainable and cost-effective method.
\end{abstract}

Keywords Ultrasonic $\cdot$ Amplitude $\cdot$ Wellbore $\cdot$ Condensate

$\begin{array}{llll}\text { Abbreviations } & l & \text { Falling ball viscometer ball falling length }(\mathrm{cm}) \\ \varnothing & \text { Porosity } & \rho_{1} & \text { Falling ball viscometer ball density }\left(\mathrm{g} / \mathrm{cm}^{3}\right) \\ k & \text { Permeability (Darcy) } & \rho_{2} & \text { Liquid density }\left(\mathrm{g} / \mathrm{cm}^{3}\right) \\ d_{g} & \text { Mean grain diameter (mm) } & t & \text { Falling ball viscometer ball falling time (s) } \\ \sigma_{D} & \text { Standard deviation of grain diameter based on } & M & \text { Mobility ratio } \\ & \text { phi unit }(\varphi & k_{r C O 2} & \text { Relative permeability of } \mathrm{CO}_{2} \\ \varphi & \text { Krumbian phi scale } & k_{r n D e c a n e} & \text { Relative permeability of nDecane } \\ \varphi^{n} & \text { Nth percentile of grain size distribution } & k & \text { Absolute permeability } \\ v & \text { Viscosity (cP) } & E_{A} & \text { Areal sweep efficiency }(\%) \\ K & \text { Constant relative to fluid } & S & \text { Saturation } \\ d & \text { Falling ball viscometer ball diameter }(\mathrm{cm}) & A & \left.\text { Area (in }{ }^{2}\right) \\ & & V & \text { Volume }(\mathrm{ml}\end{array}$

Nabilla Afzan Abdul Aziz

nabilla.aziz@utp.edu.my

1 Faculty of Engineering, Petroleum Engineering Department, Universiti Teknologi PETRONAS, 32610 Seri Iskandar,

Perak, Malaysia 


\section{Introduction}

Hydrocarbons found in gas condensate reservoirs are primarily gasses which are composed of high amounts of $\mathrm{C} 1$ to $\mathrm{C} 4$ and also heavier ended hydrocarbons. As pressure drops below dew point as in Fig. 1, liquid accumulates, and saturation of condensate increases. This will affect gas mobility as both gas and condensate will compete for flow paths. Condensate liquid saturations typically spread near the wellbore region due to drawdown below dew point pressure and restricts gas flow (Fan et al., 2005). Through time, condensate banking will accumulate in the wellbore, affect gas permeability, and thus negatively affect the productivity of a well. Under a project by Shell and Petroleum Development Oman, a production loss of $67 \%$ was exhibited for gas condensate wells located in two separate fields (Smits et al., 2001). This production loss faced shows the critical importance of overcoming effects of condensate banking.

Many forms of improved oil recovery techniques have been studied by such as in situ generation of carbon dioxide (Gumersky et al., 2000), carbon dioxide injection (Al-Abri, 2011), gas injection (Cruz Lopez, 2000), chemical injection of surfactant and polymer (Noh \& Firoozabadi, 2008), and horizontal drilling (Dehane et al., 2000). Although current improved oil recovery techniques work efficiently in recovering hydrocarbons in gas condensate reservoirs, they face a number of limitations.

Usage of carbon dioxide in improved oil recovery often causes extensive corrosion in equipment or facilities (Yevtushenko et al., 2014; Yuanhua et al., 2013) and negatively affect environmental biodiversity (Carruthers, 2014). This corrosion occurs due to the acidic nature of $\mathrm{CO}_{2}$ which can be reduced by surfactants but will lead to higher incurred costs. Wettability alterations improve immobile condensates in the wellbore by the use of surfactants. These surfactants will alter wettability in the wellbore from a liquid-wet to

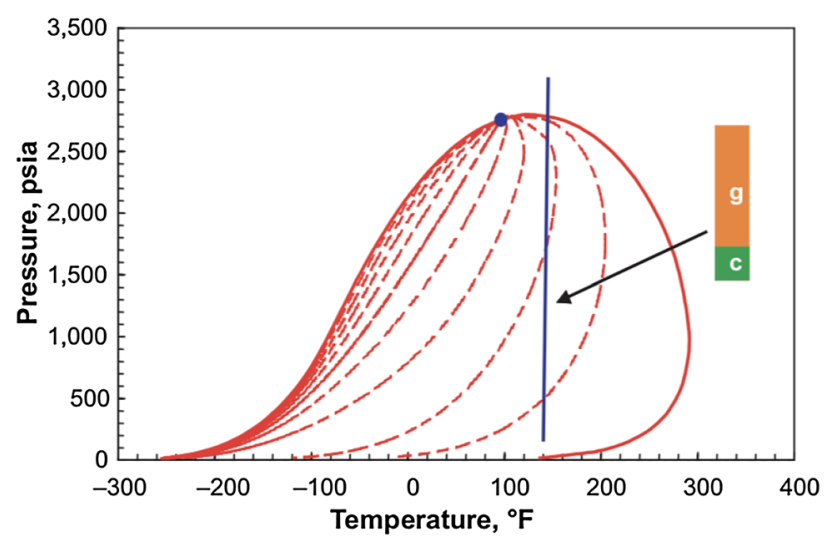

Fig. 1 Typical gas condensate phase envelope (Kamath, 2007) gas-wet. Much like surfactants, solvents may also be used in order to reduce interfacial tension by miscible displacement of condensate (Du et al., 2000). Hydraulic fracturing, which composes of the injection of water, sand, and chemicals, will increase pore connectivity. This method will induce cracks and fractures which will increase pore connectivity and enable better fluid flow from the reservoir.

These studies have been pointed out that many of the existing recovery techniques are very costly and may even cause damage to the environment (Abramova et al., 2015; Verma, 2000; Alvarado, 2010; Malik and Islam, 2000; Donaldson et al., 1985). Besides the environmental impact brought by the usage of carbon dioxide, solvents, and chemicals used in current methods of improved oil recovery, they are also extremely costly or require constant replenishment and supply of resources. Advantages of ultrasonic improved oil recovery are that it is adaptable, affordable, simple to operate, and causes no pollution to the environment (Kuznetsov et al., 2001.)

In the growth of greener recovery techniques, researchers have found mechanisms which could enable ultrasonic waves to effectively stimulate oil recovery. The underlying sonic mechanisms are cavitation (Guo et al., 2004), coalescence (Mettin et al., 1997), and micro-emulsification (Abismail, 1999). Cavitation occurs with the rapid increase and decrease in pressure which overcome a liquid's cohesive forces, forming a cavity which will fill up with dissolved gases and subsequently collapse. Coalescence is when droplets of fluid come into contact and form a single particle. However, micro-emulsification occurs when dispersed emulations in an oil-water system are in a small-scale and are a thermodynamically stable solution. Insonation toward surfactant and oil is reported to be less polydispersed and more stable based on Abimail (1999). Ramisetty and Shyamsunder (2011) reported on the microemulsion has better stability under sonic exposure; however, the findings recorded that after $60 \mathrm{~min}$, the oin in water emulsion starts to undergo demulsification.

A mechanism of great interest to this study is cavitation due to the mechanical vibrations and it causes in fluids. Physical properties of ultrasonic waves which have cycles of expansion and compression will exert negative and positive pressure on molecules, respectively. In the presence of gas, cavities form in a liquid and oscillate in size (Suslick, 1989). The cavitation will grow rapidly until it can no longer contain energy received from the ultrasonic waves and implode. Cavitation will occur in heavy oils when exposed to ultrasound and the implosion in liquid will cause mechanical vibrations (Wang et al., 2015b). As a result of these vibrations, heavy oils can be broken down into lighter hydrocarbon substances and rise in temperature which reduces oil viscosity as in Fig. 2 . The findings showed a viscosity reduction of an approximate 0.05 to $0.10 \mathrm{cp}$ with temperature 


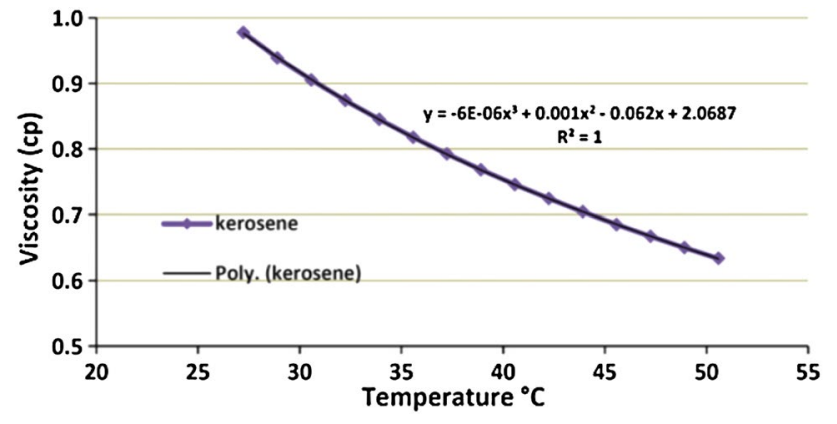

Fig. 2 Viscosity vs temperature (Mohammadian et al., 2013)

increment of every $5{ }^{\circ} \mathrm{C}$. This reduces fricitional drag on oil in reservoir. The stability of oil displacement front being displaced.

Multiple studies have been performed to further study the effectiveness of ultrasonic waves on increasing oil recovery (Hamida and Babadagli, 2007; Mohammadian et al., 2011; Hamidi et al., 2012, 2017; Alhomadhi et al., 2014; Agi et al., 2019). Porous media used in the experiments are Berea sandstone cores. This type of formation is best chosen because of the proven compatibility of sonic waves with sandstone as media. Experimental procedures are usually tailored to match real-life conditions as closely as possible. Information on glass packs, sonic and fluid used by the sonic researchers are extracted. Porosity and permeability values reported from these findings vary from 24 to $39 \%$ and 300 $\mathrm{mD}$ to $1740 \mathrm{mD}$, respectively.

Fluid properties used by previous eminent researchers indicate that many of these experiments utilize mineral oil, kerosene, Vaseline, paraffin oil, and also crude oil which range from a viscosity of $0.99 \mathrm{cP}$ to $400 \mathrm{cP}$. The densities of fluids also vary greatly from 0.73 to $1.45 \mathrm{~g} / \mathrm{cc}$. After the apparatus and materials were set up, the models were exposed to ultrasonic radiation. Ultrasonic powers used were between 0 and 500 Watts with exposure times from 90 to $18,000 \mathrm{~min}$. However, none of the studies investigated the effects of varying amplitudes on oil recovery.

$\mathrm{Xu}$ et al. (2011) stated that a strong bond molecules of heavy crude oil can be cracked due to cavitation effect by increasing the ultrasonic frequency resulted in a bubble collapse which change the behavior of heavy crude oil to light crude oil. Mohammadian et al. (2013) extended their experiment and answer the question that has been addressed by previous authors. They stated that high pressure surges are created result from bubbles collapsed. The implosion of bubbles caused the pressure to drop resulted the absolute permeability to increase. Thus, the pressure drops, which due to viscosity reduction of the oil increase the additional oil recovery, which align with previous record by Poesio et al. (2002) and has been supported by Pawar et al. (2014) regarding the relationship of cavitation effect on higher recovery.
Xianyong et al. (2004) and Jihui et al. (2006) investigated the influence of ultrasonic radiation in terms of its intensity followed by temperature effect and time interval on oil viscosity. They stated that the mechanisms stated above are related each other. As the ultrasonic radiation increases, heat will be generated result in temperature increase. The heat will break the heavy crude oil molecule to reduce the oil viscosity with the increasing treatment time. Poesio and Ooms (2005) stated that the viscosity reduction occurred as the fluid is exposed by heat that is generated from wave radiation in porous media. Mohammadian et al. (2013) agreed that fluid viscosity and interfacial tension are reduced due to temperature increase during radiation by the experiment conducted using sonification water-flooding on various oil viscosity with the effect of temperature rises is included.

Changes in crude oil rheology are investigated by Gunal and Islam (2000) when they exposed the crude oil under the ultrasonic wave radiation. The sample of a given specimen was exposed to the ultrasonic radiation with a frequency and intensity of $10 \mathrm{kHz}$ and $250 \mathrm{~W}$, respectively. They found that ultrasound treatment can change the crude oil rheology, especially in terms of its viscosity but is not efficient if the treatment is carried out with high temperature as the radiation did not yield any changes on oil viscosity. Wang et al. (2015a) extended the same experiment by Gunal and Islam (2000) on crude oil. They stated that the movement of crude oil is more fluid at lower temperature aid by heat generated from ultrasonic wave itself.

Work in this area is extensive but is primarily concerned with the additional oil recovery from the mechanism. Here, we report a neglected aspect in previous studies on wave amplitude effect to sweeping efficiency. This is an under developed area of research on maximizing usage of sonic application by tuning the wave peaks. Although no experiments were conducted by using multiple ultrasonic amplitudes as a variable, it can be proved that sonication indeed increases oil recovery as up to $16 \%$ increase in production was evident in a study by Mohammadian et al. (2011). Therefore, the application of ultrasonication in the oil and gas field is a viable option for future IOR technique.

\section{Methods and materials}

Experimental results of experiments conducted include all required project objectives which mainly focus on the efficiency of various ultrasonic amplitudes in increasing condensate recovery. Before beginning the experiment, the dimensions of sandstone cores and glass pack are thoroughly measured. The glass pack consisted of glass beads of grains ranging from $600 \mu$ to $850 \mu$. Next, using the measured dimensions, porosity and permeability measurement data were recorded for both media. These measurements are

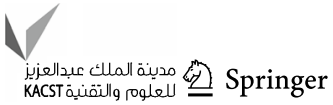


important in determining the relationship of porosity, permeability, and oil recovery. Properties of n-Decane without and with sonication were also obtained by using a viscometer and density meter.

The study was carried out in two separate experiments to evaluate the stated objectives. Experiment 1 of the project is to evaluate the effects of ultrasonic amplitudes on condensate saturated cores in static conditions. Experiment 2 is to analyze condensate removal in a heterogenous glass bead pack at different amplitudes in flowing conditions. The glass bead pack will be used to mimic a heterogenous near-wellbore condition. The right section of the glass pack resembles the wellbore vicinity in a real gas-condensate reservoir scenario. The outlet represents the inner wellbore. $\mathrm{N}$-decane is representing the condensate (liquid phase), and the flowing gas $\left(\mathrm{CO}_{2}\right)$ is simulating gas flow from the reservoir. The glass beads imitate the quartz grains between the pores of a sandstone. $\mathrm{CO}_{2}$ is used due to the gas availability in lab and to indicate 2-phase system. This study is to evaluate sonic effects in 2 phase system.

Before beginning the experiments, a few parameters were investigated to carry on with data evaluation later on. A digital weighing scale was used to measure the weight of glass pack before and after saturation in order to determine the porosity. In order to study the permeability of the porous media, a grain sieve was used to determine the glass bead grain distribution. An Anton Paar DMA $35 \mathrm{~N}$ density meter and a falling ball viscometer were used to determine density and viscosity of n-Decane before and after sonication. The experiment is conducted by fully saturating a glass pack filled with glass beads, $600 \mu-850 \mu$, with injection port as in Fig. 3, with n-Decane using a syringe pump.

The glass pack is then immersed into a water bath and exposed to no ultrasonic radiation for $60 \mathrm{~min}$ to be used as a constant. $\mathrm{CO}_{2}$ gas is then injected into the glass pack in order to produce the n-Decane and collected in a measuring cylinder. Sweeping patterns are observed during production, and amount of n-Decane produced is measured and recorded. The experiment is then repeated with exposure to ultrasonic waves

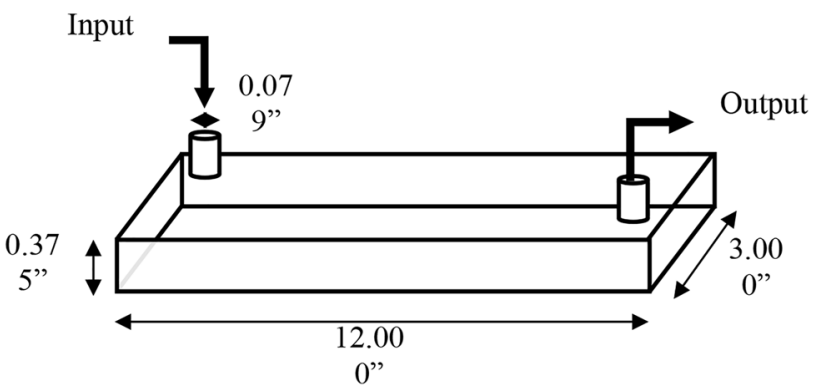

Fig. 3 Glass pack dimensions of $10 \%, 50 \%$, and $100 \%$ amplitudes, respectively, for a duration of $60 \mathrm{~min}$ and $120 \mathrm{~min}$.

\section{Glass pack porosity}

In order to calculate the porosity of the glass pack, calculations were done by measuring the ratio of occupied liquids in glass pack and the weight of glass pack. In order to reduce possibilities of error, all data are measured three times and results are as tabulated in Table 1. Case 1 indicates glass pack without glass beads, Case 2 indicates glass pack with glass beads, and Case 3 indicates glass pack with water saturated glass beads.

$\varnothing=\frac{\text { Case } 3-\text { Case } 2}{\text { Case } 2-\text { Case } 1}$

$\varnothing=0.25$

Thus, the porosity measured from the glass pack was calculated using Eq. (1) to be 0.25 which indicated that the porous media used are found to have $25 \%$ allowable fluid storage.

\section{Glass pack permeability}

Size of the glass beads was measured by sieving in order to get the accurate range of sizes to attain a graph of grain size distribution which is widely used for geotechnic studies. It is possible to calculate the permeability using Eq. (2) which is greatly affected by the formation grain distribution. In this classification of grain sizes, the Wentworth grade scale is used to determine the class of particle. The size ranges from $0.60 \mathrm{~mm}$ to $0.85 \mathrm{~mm}$, and the particle can be determined as course sand (Yang, et al., 2007). Grain diameter attained from sieving was tabulated, and the cumulative weight percentage was calculated in order to form a graph of size distribution in Fig. 4 based on methods in Bunte and Abt (2001) Table 2.

$k=760 d_{g}^{2} e^{\left(-1.31 \sigma_{D}\right)}$

$d_{g}=\frac{d_{\max }+d_{\min }}{2}$

$\sigma_{D}=\frac{\varphi 84-\varphi 16}{4}+\frac{\varphi 95-\varphi 5}{6.6}$

Table 1 Glass pack weight

\begin{tabular}{llll}
\hline Reading & Case $1(\mathrm{~g})$ & Case 2 $(\mathrm{g})$ & Case 3 $(\mathrm{g})$ \\
\hline 1 & 224.26 & 291.93 & 308.85 \\
2 & 224.27 & 291.94 & 308.85 \\
3 & 224.27 & 291.93 & 308.85 \\
Average & 224.27 & 291.93 & 308.85 \\
\hline
\end{tabular}


$\varphi=-\log _{2} d$

From the calculated data, we can determine that the sorting class is very well sorted (Bunte and Abt, 2001). This is because of its standard deviation of 0.178 falls under very well sorted which is less than 0.35 to 0.50 range that indicates well-sorted category, based on Folk and Ward's (1957) classification of the degree of sorting. The permeability value attained is 316.389 Darcy $(316,389 \mathrm{mD})$ which is close to the permeability used in a study from Mohammadian et al. (2011). This proves that the initial assumption of glass pack being a representative of near-wellbore conditions is valid. The calculated value is greater than $1000 \mathrm{mD}$ and is considered to be exceptionally permeable (Folk, 1980). Permeability of the sand pack is significantly higher (1-2 orders of magnitude) than typical field conditions. For well sorted, unconsolidated pack used in labs the reported permeability is consistent with other researchers.

\section{Specific gravity of $\mathbf{n}$-decane}

In order to determine the viscosity, density of n-Decane is measured. N-Decane was sonicated in beaker at amplitudes of 100 percent. The needle of the density meter was submerged into n-Decane in order for the pump to allow fluid to flow up the needle to calculate its density. This was repeated three times to acquire the most accurate readings as in Table 3.

\section{Results}

Experimental designs were based on the scope of production in a green field to provide remedial measures against premature productivity decline. When indications of condensate banking become apparent from decline in productivity, the well is to be shut-in in order to carry out sonication in the near-wellbore region. After sonication, the well is allowed to flow naturally. The effects of ultrasonic waves of varying amplitudes on condensate removal and how it affects condensate mobility and sweeping efficiency in the near-wellbore region will be analyzed. Therefore, experiments of ultrasonic amplitudes on a glass pack of varying grain sizes shall be conducted in order to determine the amount of possible recoverable hydrocarbons in gas condensate reservoirs after varied durations of ultrasonic exposure. In order to simulate near-wellbore conditions and measure final condensate mobility, glass packs of varied grain sizes will be saturated with n-Decane. Ultrasonic waves will be fixed at $20 \mathrm{kHz}, 20$ Watts, and the amplitude applied will be at intervals of $10 \%, 50 \%$, and $100 \%$. The experiment will be performed twice in order to determine the relationship between duration of ultrasonic exposure and amount of hydrocarbon recoverable. The most effective parameters will be observed, recorded, and analyzed.

Following that in order to determine the effectiveness of ultrasonic radiation on removal of condensate banking, the following parameters were observed, calculated, and evaluated:

i. Mobility ratio

ii. Sweeping efficiency

iii. Oil recovery

Hamida and Babadagli (2007) and Hamidi et al. (2012) provide setup of core study under sonic using imbibition cells. The setup for displacement study of ultrasonic-based oil recovery in this study is based on Mohammadian et al. (2011) and Alhomadhi and Almobarky (2013). These studies shared similar setup from the aspects of core or sandpack saturation, sonic exposure and measurement of oil recovery. The setup was further improved for this study in order to imitate a gascondensate system with the availability of glasswares and apparatus in the lab.

\section{Mobility ratio}

\section{Viscosity change under sonication of $\mathbf{n}$-decane}

Prior understanding of viscosity change under sonication is necessary to correctly interpret the results. It has been reported by several eminent researchers that temperature is induced in the sonicated liquid during the sonic exposure. We investigated to ensure how significant the temperature change is. The result showed there is a slight viscosity reduction for 0.6 multiplication of temperature increase (from $28{ }^{\circ} \mathrm{C}$ to $45^{\circ} \mathrm{C}$ ) which is $0.02 \mathrm{cP}$. The viscosity of the condensate liquid experience infinitesimal change, at increasing amplitude of sonication. The maximum operating condition of the ultrasonic equipment of $120 \mathrm{~min}$ and $100 \%$ amplitude reported a viscosity reduction of $0.02 \mathrm{cp}$ and the temperature was $45^{\circ} \mathrm{C}$.

By using the falling ball viscometer, viscosity values of $\mathrm{n}$-Decane before and after sonication of $20 \mathrm{kHz}, 20 \mathrm{~W}$, and $100 \%$ amplitude. Duration of ultrasonic exposure was set to $120 \mathrm{~min}$. The test was conducted in order to later calculate the mobility to determine effectiveness of the ultrasonication on the removal of condensate banking in near-wellbore conditions. A typical Fenn Viscometer cannot be used in this experiment due to the low sensitivity of the Fenn Viscometer scale Table 4.

$v=K\left(\rho_{1}-\rho_{2}\right) \bullet t$

$K=\frac{g d^{2}}{18 l}$ 
Fig. 4 Glass bead size distribution. Data attained were analyzed as shown in Table 2 by calculating the permeability of glass pack using Eqs. (2) to (5)

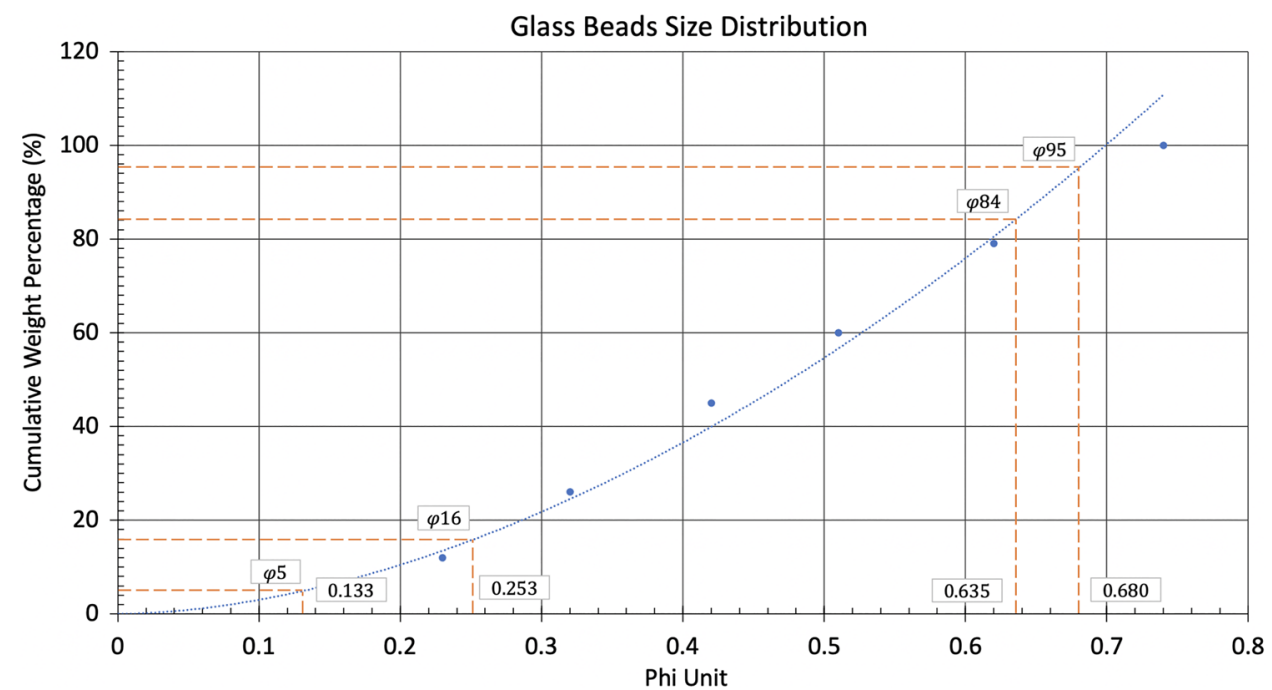

Glass Beads Size Distribution

\begin{tabular}{lr}
\hline Calculated parameters & \multicolumn{1}{c}{ Values } \\
\hline$\sigma_{D}$ & 0.178 \\
$d_{g}(\mathrm{~mm})$ & 0.725 \\
$k$ (Darcy) & 316.389 \\
\hline
\end{tabular}

Table 3 Specific density measurements

\begin{tabular}{ll}
\hline Reading & Density $\left(\mathrm{g} / \mathrm{cm}^{3}\right)$ \\
\hline 1 & 0.738 \\
2 & 0.735 \\
3 & 0.740 \\
Average & 0.738 \\
\hline
\end{tabular}

Table 4 Viscosity measurements

\begin{tabular}{llc}
\hline Ball falling time (s) & $\begin{array}{l}\text { Without sonication } \\
\left(28^{\circ} \mathrm{C}\right)\end{array}$ & $\begin{array}{l}\text { With sonica- } \\
\text { tion }\left(45^{\circ} \mathrm{C}\right)\end{array}$ \\
\hline Reading 1 & 137.32 & 128.94 \\
Reading 2 & 137.58 & 130.27 \\
Reading 3 & 136.00 & 130.62 \\
Average & 136.97 & 129.94 \\
Viscosity (cP) & 0.383 & 0.363 \\
\hline
\end{tabular}

As proven in the above table using Eq. (6), due to increase in temperature during sonication, a change in viscosity can be observed in the fluid. The most likely cause is ultrasonic cavitation which occurs in the n-Decane on a microscopic level. When natural cohesive forces of a liquid are overcome by negative liquid pressure in the rarefraction region of a wave, cavitation occurs (Hamidi et al., 2014). Due to this, the higher the initial viscosity of a fluid, the bigger the amplitude needed to overcome
Table 5 Relative permeability dataset without sonication

\begin{tabular}{lll}
\hline Relative permeability & $\mathrm{S}_{\text {n-Decane }}(\%)$ & $\mathrm{S}_{\mathrm{CO} 2}(\%)$ \\
\hline 1.00 & - & 0 \\
0.90 & 80 & 10 \\
0.60 & 75 & 25 \\
0.40 & 50 & 50 \\
0.10 & 25 & 75 \\
0.00 & 10 & 80 \\
\hline
\end{tabular}

cohesive forces in fluids such as gas condensates as represented by $n$-Decane. Thus, the change in fluid viscosity will influence the mobility of condensate in the formation. The mobility of condensate liquid is slightly increase; however, it exhibits reduced frictional drag due to reduced viscosity in the porous media.

Lowest and highest recoverable amount of n-Decane is determined as $9.5 \mathrm{ml}$ without sonication and $17.39 \mathrm{ml}$ with sonication of $100 \%$ amplitude for $120 \mathrm{~min}$. By observing the glass pack throughout $\mathrm{CO}_{2}$ flow, fluid saturation and relative permeabilities are estimated. As accurate values were not possible to be attained from visual observation alone, relative permeability data (Table 5) from the experiment without sonication were used to calculate both mobility ratios for no sonication and with sonication of $100 \%$ amplitude for $120 \mathrm{~min}$. The absolute permeability for three Berea sandstone cores of the same length was completely saturated with n-Decane with a core saturator. Permeability of all 3 cores was measured using a POROPERM instrument. The permeability recorded were $567.22 \mathrm{mD}, 563.48 \mathrm{mD}$ and 589.48 $\mathrm{mD}$. The average permeability is $573.39 \mathrm{mD}$. From this data, a graph of relative permeability against saturation was plot in Fig. 5. The mobility ratio without and with sonication is calculated using Eq. (10). 
Mobility $=\frac{\text { Permeabilityofrocktofluid }}{\text { fluidviscosity }}$

$M=\frac{\text { Mobilityof } \mathrm{CO}_{2}}{\text { MobiltyofnDecane }}$

$M=\frac{\frac{k k r_{\mathrm{CO}_{2}}}{\mu_{\mathrm{CO}_{2}}}}{\frac{k k r_{n \text { Decane }}}{\mu_{\text {nDecane }}}}=\frac{k_{r \mathrm{CO}_{2}} \times \mu_{\text {nDecane }}}{k_{\text {rnDecane }} \times \mu_{\mathrm{CO}_{2}}}$

$k_{r}=\frac{k_{n \text { Decaneor } \mathrm{CO}_{2}}}{k}$

Figure 5 indicates the plot of unsteady-state relative permeability against $n$-Decane saturation. In order to evaluate the relative permeability values of $n$-Decane and $\mathrm{CO}_{2}$ at $75 \%$ $\mathrm{n}$-Decane saturation, it was estimated that $\mathrm{k}_{\mathrm{rCO} 2}$ is 0.10 and $\mathrm{k}_{\mathrm{rnDecane}}$ is 0.60 .

Calculation of mobility ratio is achieved by using a viscosity of $0.01508 \mathrm{cP}$ for $\mathrm{CO}_{2}$ at $28{ }^{\circ} \mathrm{C}$ based on online reported value for $\mathrm{CO}_{2}$ gas at varying pressure and temperature (Engineering Toolbox, 2018). These values are used together with $0.383 \mathrm{cP}$ and $0.363 \mathrm{cP}$ for n-Decane without and with sonication, respectively, as calculated by using the falling ball viscometer. A system's areal sweep efficiency will increase with an increase in reciprocal mobility ratio (1/M) (Lyons, 2009). Proven in Eq. (8), as n-Decane viscosity decreases, n-Decane mobility will increase which will cause a reduction in the mobility ratio of the system. This shows that the decrease in mobility ratio calculated corresponds to the calculated areal sweep efficiency in the next section.

\section{Sweeping efficiency}

Another important factor to observe is the sweeping efficiency of the system before and after sonication. To determine this, the flow of $\mathrm{CO}_{2}$ through the glass pack was recorded on camera and observed. The flow was redrawn in a simple diagram as shown in Fig. 6 and Fig. 7. The glass pack has a length of $12.000 \mathrm{in}$, height of $0.375 \mathrm{in}$, and width of 3.000 in and the pack is being divided with equivalent cells of $25 \times 6.5$ cells. The size of each cell is $0.48 \times 0.46 \mathrm{in}$. The n-Decane was dyed with a red dye to distinguish the different types of fluid in the $\mathrm{CO}_{2}$-decane system and to monitor the $\mathrm{CO}_{2}$ flow. Figure 8 indicates labeling to calculate areal sweep efficiency $\left(E_{A}\right) . E_{A}$ is calculated as the following:

$E_{A}=\frac{S_{A D O}}{S_{A B C}}$
$E_{A}=\frac{A_{A D O}}{A_{A B C}}$

Amplitude 10\% reported in the experiment indicates sweeping efficiency similar to no sonication, and increasing ampliture lead to higher sweep efficiency. The highest amplitude result was extracted and displayed. Adobe was used to select the area marked in red for the purpose of recolor the images in Fig. 3 and 4. Tolerance of selection was adjusted until the most similar amount of red area was selected. It was then filled in with red and the remaining filled in with blue.

Table 6 shows the respective areal sweep efficiency before and after sonication which are $53.11 \%$ at a sweeping area of $19.12 \mathrm{inch}^{2}$ and $77.44 \%$ at a sweeping area of $27.88 \mathrm{inch}^{2}$. This indicates an increase of $24.33 \%$ in sweep efficiency after glass pack sonication. The increase in stability of the fluid front plays a great role in the improved recovery of n-Decane (Hamidi et al., 2017). A lower residual oil saturation is able to be reached together with a high sweeping efficiency. Sweeping efficiency in the glass pack without sonication showed a viscous fingering effect due to the unfavorable mobility ratio of $\mathrm{CO}_{2}$ and n-Decane. However, after sonication, it was found to have improved as viscosity of n-Decane was reduced which allowed the $\mathrm{CO}_{2}$ gas to travel through the glass pack without bypassing n-Decane.

Therefore, sweep efficiency increases with increasing sonic amplitude due to the change of fluid viscosity occurred in the porous media. Sohrabi and Jamiolahmady (2009) reported that the equilibrium position of a gas-condensate interface is affected by the application of ultrasonic energy leading to an induced flow. It is, therefore, conceivable that in a network of pores in a porous medium where the movement of gas is hampered by liquid (condensate), ultrasonic radiation could improve the flow by opening up some of the pores restricted by condensate.

\section{Decane recovery}

After sonication of varying degrees of amplitudes of $10 \%$, $50 \%$ and $100 \%$, the data obtained were collected and analyzed. The volume of n-Decane collected is tabulated in Table 7 and analyzed in order to determine the recoverable amount after sonication at various amplitudes and exposure durations. Without sonication, it can be observed that there is a recovery of only $9.5 \mathrm{ml}$ after gas is flowed through the glass pack. However, after exposure to ultrasonic radiation for $120 \mathrm{~min}$ at $100 \%$ amplitude, the amount of recoverable hydrocarbons increased to $13.5 \mathrm{ml}$ as recorded in Table 7 . Based on the recoverable n-Decane amount through the outlet port, it is further converted to percentage as recorded in Table 8. 


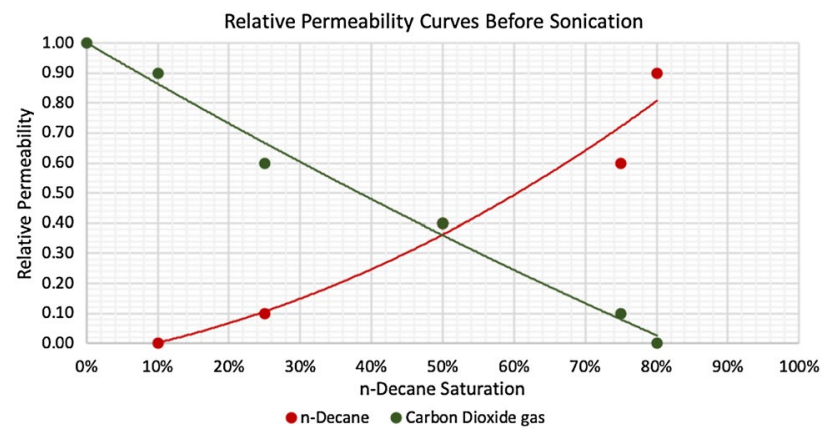

Fig. 5 Relative permeability against saturation

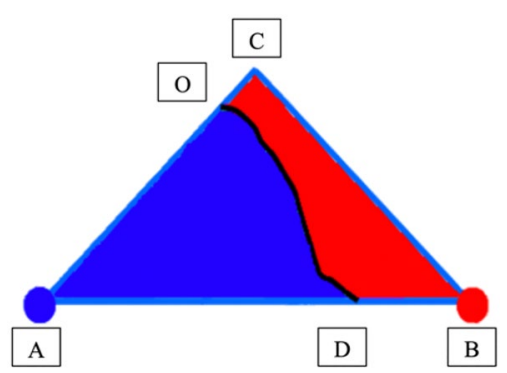

Fig. 6 a Areal sweeping nefore sonication and $\mathbf{b}$ simplified drawing before sonication

The percentage recovery of N-Decane was calculated using Eq. 14 and plotted against ultrasonic amplitude, as shown in Fig. 8.

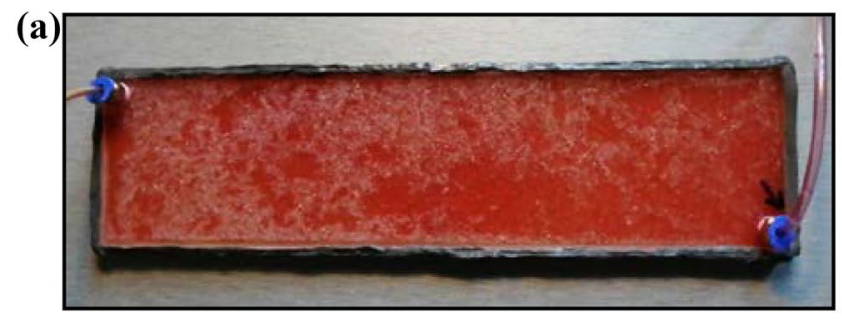

$\operatorname{Recovery}(\%)=\frac{V_{0 \% \text { amplitude }}-V_{n \% \text { amplitude }}}{V_{0 \% \text { amplitude }}+V_{n \% \text { amplitude }}}$

Comparing between the difference in amplitude of both duration cases, sonication of $100 \%$ will result in a higher percentage of recovery which surpasses all lower amplitudes. However, when taking time into consideration, a higher duration of exposure to ultrasonic radiation with an amplitude of $100 \%$ will result in the highest recovery of $17.39 \%$.

Figure 9 shows the graphical representation on the relationship between degree of ultrasonic amplitude, duration and liquid condensate recovery. Due to highest recovery percentage reported at $100 \%$ amplitude, it can be concluded that sonication at the highest amplitude and long exposure duration is the best option in removing condensate banking. The results found were possible due to decrease in viscosity as discussed in mobility ratio section. The higher the initial viscosity of a fluid, the bigger the amplitude needed to overcome cohesive forces in fluids such as gas condensates as represented by $n$-Decane. Thus, the change in fluid viscosity will influence the mobility of condensate in the formation. However, further study is recommended for optimization study on exposure time and amplitude, under reservoir condition and to utilize consolidated samples.

The results of the experiment are due to the mechanisms of ultrasonic exposure which is mainly cavitation. Cavitation causes oscillation of pressure in the fluid which results in mechanical vibrations. These mechanical vibrations cause temperature to increase which leads to

Fig. 7 a Areal sweeping after sonication and $\mathbf{b}$ simplified drawing after sonication

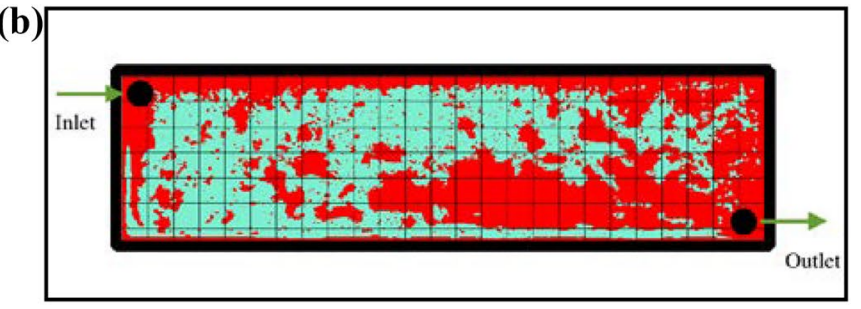

(a)

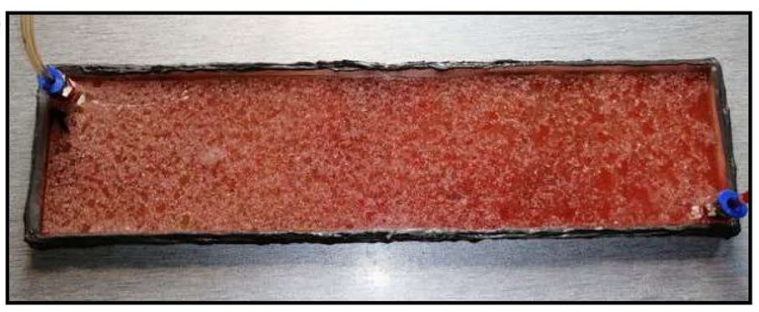

Fig. 8 Areal sweep efficiency (EA) labels (Mohammadian et al., 2013)

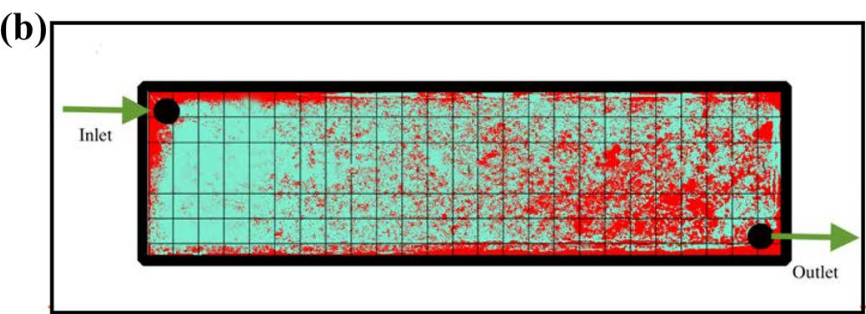

1

مدينة الملك عبدالعزيز

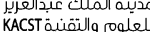


Table 6 Parameters of areal sweeping before and after sonication

\begin{tabular}{llll}
\hline & Parameters & $\begin{array}{l}\text { Calculated } \\
\text { Values }\end{array}$ & $E_{A}(\%)$ \\
\hline Before sonication & Sweeping area $\left(\mathrm{inch}^{2}\right)$ & 19.12 & 53.11 \\
& Top planar area $\left(\mathrm{inch}^{2}\right)$ & 36.00 & \\
After sonication & Sweeping area $\left(\mathrm{inch}^{2}\right)$ & 27.88 & 77.44 \\
& Top planar area $\left(\mathrm{inch}^{2}\right)$ & 36.00 & \\
\hline
\end{tabular}

Table 7 Recoverable amount of n-decane

\begin{tabular}{lllll}
\hline Time (mins) & \multicolumn{4}{l}{ Volume (ml) at ultrasonic amplitudes of } \\
\cline { 2 - 5 } & No sonication & $10 \%$ & $50 \%$ & $100 \%$ \\
\hline 60 & 9.5 & 10.5 & 11.0 & 11.5 \\
120 & 9.5 & 11.5 & 12.0 & 13.5 \\
\hline
\end{tabular}

Table 8 Percentage recovery of $n$-decane

\begin{tabular}{llll}
\hline Time (mins) & \multicolumn{3}{l}{ Recovery (\%) at ultrasonic amplitudes of } \\
\cline { 2 - 4 } & $10 \%$ & $50 \%$ & $100 \%$ \\
\hline 60 & 5.00 & 7.32 & 9.52 \\
120 & 9.52 & 11.63 & 17.39 \\
\hline
\end{tabular}

viscosity reduction. With the reduction in viscosity, a better sweeping efficiency is achieved which causes better overall recovery.

The disruption to the equal forces in fluid saturated system due to the effects of sonic forces to the interface of gas-condensate has positive influence. This is aligned with the findings by Sohrabi and Jamiolahmady (2009) that highlighted the interfacial tension increases with the condensate forming bridges at the pore throats, causes a reduction in gas flow, and hence productivity loss. The condensate phase is able to be mobilized due to the mechanical acoustic waves that is able destabilise the gas-condensate interface. Karami et al. (2020) conducted several studies with characterisation on the hydrocarbon chain after exposure of sonic waves. The findings indicate that ultrasonic treatment is recommended in the blocked formations with higher acoustic impedence. The team highlighted the significant impact of increasing wave frequency which induces pressure disturbance in the blocked formations. This shows that condensate banking could be removed effectively by using ultrasonic recovery.
Fig. 9 Recovery against ultrasonic amplitude

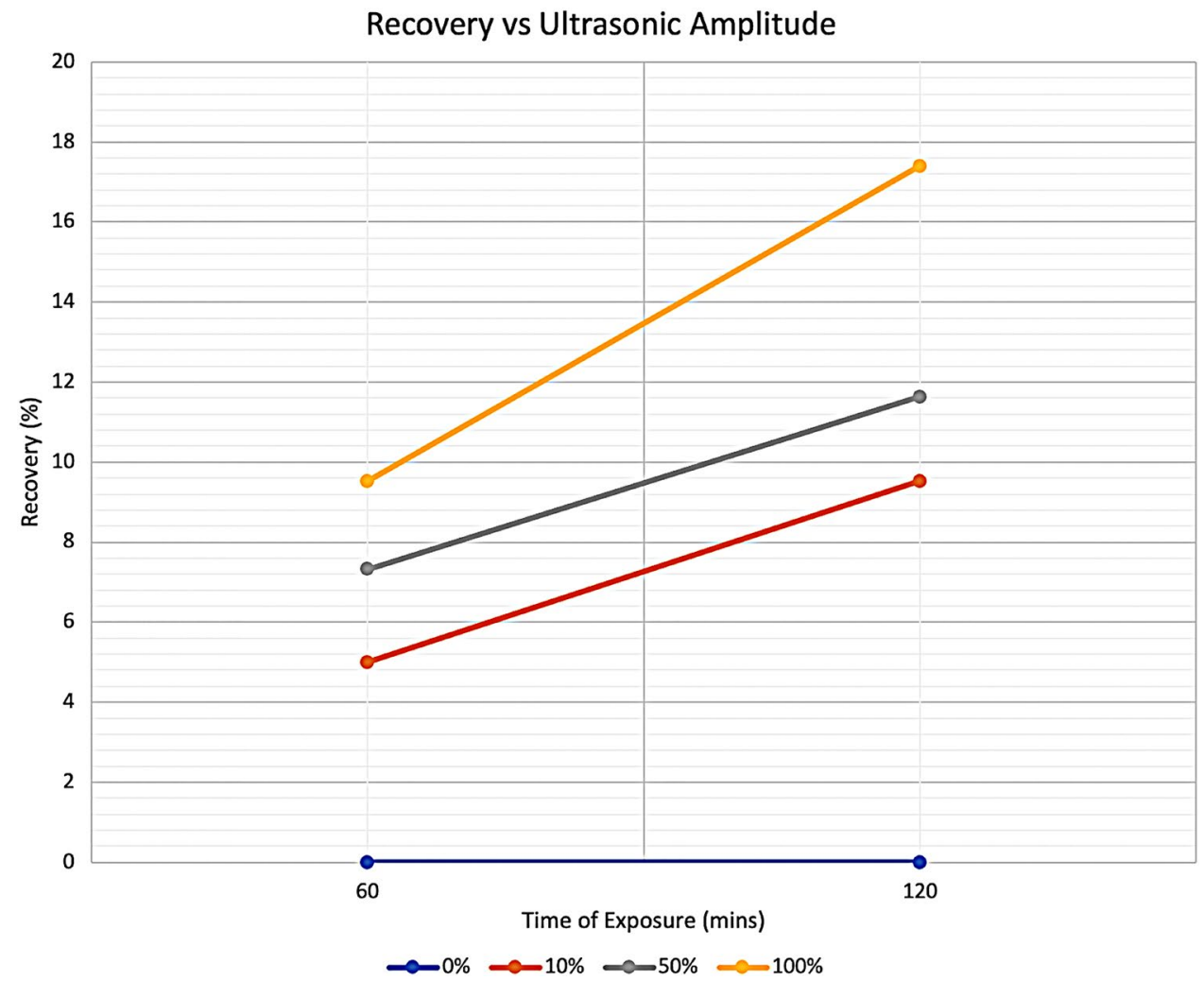




\section{Conclusions}

Sonication provides mechanical vibrations to the fluid which causes cavitation and consequently creates mechanical vibrations leading to increased fluid temperature. Application of ultrasonic amplitudes of $100 \%$ for $120 \mathrm{~min}$ showed remarkable increase in condensate recovery for a gas condensate system. This is due to the reduction in heavy oil viscosity caused by the increase in temperature which occurs with sonication. Due to continuous sonic exposure, it leads to increased temperature and reduction in viscosity, and the sweeping efficiency is also improved from a viscous fingering pattern to a piston like displacement through the glass pack. This indicates that mobility of n-Decane is improved after sonication to allow higher hydrocarbon liquid production. Insights into the aspects of the mechanical wave are expected to contribute to a better understanding of tuning the sonic wave, to deliver remarkable results in a closed solid and fluid system.

Acknowledgements The authors would like to express their gratitude to Emeritus Professor Dr Ahmad Kamal Idris for conceptualization and feedbacks on the project. The authors fully acknowledged PETRONAS Research Fund (PRF) and Universiti Teknologi PETRONAS for the approved fund which makes this important research viable and effective.

Funding This research is supported by Yayasan Universiti Teknologi PETRONAS-Fundamental Research Grant (YUTP-FRG), 0153AA-E42.

\section{Declarations}

Conflict of interest On behalf of all the co-authors, the corresponding author states that there is no conflict of interest.

Open Access This article is licensed under a Creative Commons Attribution 4.0 International License, which permits use, sharing, adaptation, distribution and reproduction in any medium or format, as long as you give appropriate credit to the original author(s) and the source, provide a link to the Creative Commons licence, and indicate if changes were made. The images or other third party material in this article are included in the article's Creative Commons licence, unless indicated otherwise in a credit line to the material. If material is not included in the article's Creative Commons licence and your intended use is not permitted by statutory regulation or exceeds the permitted use, you will need to obtain permission directly from the copyright holder. To view a copy of this licence, visit http://creativecommons.org/licenses/by/4.0/.

\section{References}

Abisma1l B, Canselier JP, Wilhelm AM, Delmas H, Gourdon C (1999) Emulsification by ultrasound: drop size distribution and stability. Ultrason Sonochem 6(1-2):75-83
Abramova AV, Abramov VO, Kuleshov SP, Timashev EO (2015) Analysis of the modern methods for enhanced oil recovery. Energy Sci Technol 3:118-148

Agi A, Junin R, Shirazi R, Afeez G, Yekeen N (2019) Comparative study of ultrasound assisted water and surfactant flooding. J King Saud Univ Eng Sci 31(3):296-303

Al-Abri, A.S., 2011. Enhanced gas condensate recovery by $\mathrm{CO} 2$ injection (Doctoral dissertation, Curtin University).

Alhomadhi E, Amro M, Almobarky M (2014) Experimental application of ultrasound waves to improved oil recovery during waterflooding. J King Saud Univ Eng Sci 26(1):103-110

Alvarado V, Manrique E (2010) Enhanced oil recovery: an update review. Energies 3(9):1529-1575

Bunte, K. and Abt, S.R. 2001. Sampling surface and subsurface particle-size distributions in wadable gravel-and cobble-bed streams for analyses in sediment transport, hydraulics, and streambed monitoring. US Department of Agriculture, Forest Service, Rocky Mountain Research Station.

Cao, R., Zhou, Y., \& Xiong, Q. 2013, December. The Research on Evaluation of Areal Sweep Efficiency in Low Permeability Reservoir with Streamline Numerical Simulation Method. In AASRI Winter International Conference on Engineering and Technology (AASRI-WIET 2013). Atlantis Press.

Carruthers, K. 2014. Environmental Impacts of $\mathrm{CO}_{2}$ EOR. Scottish Carbon Capture and Storage (SCCS).

Cruz Lopez, J.A., 2000, February. Gas Injection As A Method For Improved Recovery In Gas-Condensate Reservoirs With Active Support. In SPE International Petroleum Conference and Exhibition in Mexico. OnePetro.

Dehane, A., Tiab, D. and Osisanya, S.O., 2000, November. Performance of Horizontal Wells in Gas-Condensate Reservoirs, Djebel Bissa Field, Algeria. In SPE/CIM International Conference on Horizontal Well Technology. OnePetro.

Donaldson EC, Chilingarian GV, Yen TF (1985) Enhanced oil recovery, I: fundamentals and analyses. Elsevier

Du, L., Walker, J.G., Pope, G.A., Sharma, M.M. and Wang, P., 2000, October. Use of solvents to improve the productivity of gas condensate wells. In SPE annual technical conference and exhibition. OnePetro.

Engineering ToolBox, (2018). Carbon Dioxide - Dynamic and Kinematic Viscosity. [online] Available at: https://www.engineerin gtoolbox.com/carbon-dioxide-dynamic-kinematic-viscositytemperature-pressure-d_2074.html [15 April 2019].

Fan L, Harris BW, Jamaluddin A, Kamath J, Mott R, Pope GA, Shandrygin A, Whitson CH (2005) Understanding Gas-Condensate Reservoirs. Oilfield Rev 17(4):14-27

Folk RL, Ward WC (1957) Brazos River bar [Texas]; a study in the significance of grain size parameters. J Sediment Res 27(1):3-26

Folk, R.L. 1980. Petrology of sedimentary rocks. Hemphill publishing company.

Gumersky, K.H., Dzhafarov, I.S., Shakhverdiev, A.K. and Mamedov, Y.G., 2000, October. In-situ generation of carbon dioxide: New way to increase oil recovery. In SPE European Petroleum Conference. OnePetro.

Gunal OG, Islam MR (2000) Alteration of asphaltic crude rheology with electromagnetic and ultrasonic irradiation. J Petrol Sci Eng 26(1-4):263-272

Guo, X., Du, Z., Li, G. and Shu, Z. 2004, January. High frequency vibration recovery enhancement technology in the heavy oil fields of China. In SPE International Thermal Operations and Heavy Oil Symposium and Western Regional Meeting. Society of Petroleum Engineers.

Hamida T, Babadagli T (2007) Analysis of capillary interaction and oil recovery under ultrasonic waves. Transp Porous Media 70(2):231-255 
Hamidi H, Haddad AS, Mohammadian E, Rafati R, Azdarpour A, Ghahri P, Ombewa P, Neuert T, Zink A (2017) Ultrasoundassisted CO2 flooding to improve oil recovery. Ultrason Sonochem 35:243-250

Hamidi H, Mohammadian E, Junin R, Rafati R, Azdarpour A, Junid M, Savory RM (2014) The effect of ultrasonic waves on oil viscosity. Pet Sci Technol 32(19):2387-2395

Hamidi H, Rafati R, Junin RB, Manan MA (2012) A role of ultrasonic frequency and power on oil mobilization in underground petroleum reservoirs. J Petrol Explor Product Technol 2(1):29-36

Jihu, W., Guokun, Q. and Longtang, Z., 2006. Study on the effect of ultrasound on the oil viscosity. J. Shengli Oilfield Staff Univ, pp.1008-8083.

Kamath J (2007) Deliverability of gas-condensate reservoirsfield experiences and prediction techniques. J Petrol Technol 59(04):94-99

Karami, S., Dehaghani, A.H.S. and Mousavi, S.A.H.S., 2020. Condensate blockage removal using microwave and ultrasonic waves: Discussion on rock mechanical and electrical properties. Journal of Petroleum Science and Engineering, 193, p.107309.

Kuznetsov OL, Simkin EM, Chillingar J (2001) Physical principles of vibrational and acoustic treatment of oil and gas reservoirs. Mir, Moscow

Lyons, W. 2009. Working Guide to Reservoir Engineering ( $1^{\text {st }}$ ed.). Gulf Professional Publishing.

Mai A, Kantzas A (2010) Mechanisms of heavy oil recovery by low rate waterflooding. J Can Pet Technol 49(03):44-50

Malik, Q.M. and Islam, M.R. 2000, January. CO2 Injection in the Weyburn field of Canada: optimization of enhanced oil recovery and greenhouse gas storage with horizontal wells. In SPE/ DOE improved oil recovery symposium. Society of Petroleum Engineers.

Mettin R, Akhatov I, Parlitz U, Ohl CD, Lauterborn W (1997) Bjerknes forces between small cavitation bubbles in a strong acoustic field. Phys Rev E 56(3):2924

Mohammadian E, Junin R, Rahmani O, Idris AK (2013) Effects of sonication radiation on oil recovery by ultrasonic waves stimulated water-flooding. Ultrasonics 53(2):607-614

Mohammadian, E., Shirazi, M.A. and Idris, A.K. 2011, January. Enhancing oil recovery through application of ultrasonic assisted waterflooding. In SPE Asia Pacific Oil and Gas Conference and Exhibition. Society of Petroleum Engineers.

Noh MH, Firoozabadi A (2008) Wettability alteration in gas-condensate reservoirs to mitigate well deliverability loss by water blocking. SPE Reservoir Eval Eng 11(04):676-685

Pawar IA, Joshi PJ, Kadam AD, Pande NB, Kamble PH, Hinge SP, Banerjee BS, Mohod AV, Gogate PR (2014) Ultrasound-based treatment approaches for intrinsic viscosity reduction of polyvinyl pyrrolidone (PVP). Ultrason Sonochem 21(3):1108-1116

Poesio, P. and Ooms, G., 2005. Influence of high-frequency acoustic waves on the flow of a liquid through porous material: experimental and theoretical investigation. In IUTAM Symposium on Physicochemical and Electromechanical Interactions in Porous Media (pp. 61-66). Springer, Dordrecht.

Poesio, P., Ooms, G., Schraven, A. and van der Bas, F., 2002. Theoretical and experimental investigation of acoustic streaming in a porous material. Physical review E, 66(1), p.016309.

Ramisetty, K.A. and Shyamsunder, R., 2011. Effect of ultrasonication on stability of oil in water emulsions. International Journal of Drug Delivery, 3(1).

Sohrabi M, Jamiolahmady M (2009) Application of ultrasonic irradiation for well deliverability improvement in gas-condensate reservoirs. J Petrol Sci Eng 64(1-4):88-94

Smits, R. M. M., Van der Post, N., \& Al Shaidi, S. M. (2001, January). Accurate prediction of well requirements in gas condensate fields. In SPE Middle East Oil Show. Society of Petroleum Engineers.

Suslick KS (1989) The chemical effects of ultrasound. Sci Am 260(2):80-87

Verma, M. K. 2000. The significance of field growth and the role of enhanced oil recovery. US Geological Survey Fact Sheet FS-115-00.

Wang Z, Xu Y, Bajracharya S (2015a) The comparison of removing plug by ultrasonic wave, chemical deplugging agent and ultrasound-chemical combination deplugging for near-well ultrasonic processing technology. Ultrason Sonochem 27:339-344

Wang Z, Xu Y, Suman B (2015b) Research status and development trend of ultrasonic oil production technique in China. Ultrason Sonochem 26:1-8

Xianyong D, Ping Z (2004) Study on viscosity reduction test in Shengli offshore oil ultrasonic. Oil Gas Storage Transp 23(3):32-35

Xu, H.X., Pu, C.S., Zhao, S.S., Li, Y.H. and Shen, H.N., 2011. Experimental study and application of high power ultrasonic treatment for removal of near wellbore paraffin precipitation damage. Journal of Southwest Petroleum University(Science \& Technology Edition), 33(5), pp.146-151.

Yang, T., Fevang, O., Christoffersen, K.R. and Ivarrud, E., 2007, January. $\mathrm{LBC}$ viscosity modeling of gas condensate to heavy oil. In SPE Annual Technical Conference and Exhibition. Society of Petroleum Engineers.

Yevtushenko O, Bettge D, Bohraus S, Bäßler R, Pfennig A, Kranzmann A (2014) Corrosion behavior of steels for CO2 injection. Process Saf Environ Prot 92(1):108-118

Yuanhua L, Dajiang Z, Dezhi Z, Yuanguang Y, Taihe S, Kuanhai D, Chengqiang R, Deping Z, Feng W (2013) Experimental studies on corrosion of cement in $\mathrm{CO} 2$ injection wells under supercritical conditions. Corros Sci 74:13-21

Publisher's Note Springer Nature remains neutral with regard to jurisdictional claims in published maps and institutional affiliations. 